\title{
SUBJECTLESS IMAGES: VISUALIZATION OF MIGRANTS IN CROATIAN AND SLOVENIAN PUBLIC BROADCASTERS' ONLINE NEWS
}

\author{
Andreja Vezovnik, Faculty of Social Sciences, University of Ljubljana, Ljubljana, Slovenia \\ Ljiljana Šarić, ILOS, University of Oslo, Oslo, Norway
}

\begin{abstract}
This article explores how migrants were visually presented during the so-called migration crisis in southeast Europe in the fall of 2015. It considers photographs from two public broadcasters' news portals: Slovenia's rtvslo.si and Croatia's hrt.hr. The focus is on a specific category of images we label subjectless images; that is, images visually representing migrants and migration that avoid showing migrants as subjects. In these images, subjects are substituted by objects that metaphorically, metonymically, or symbolically stand for migrants and migration. The article explores the ideological operation of subjectless images, which operates through the logic of substituting human subjects with metaphorical, metonymic, and symbolic objects. What is presented to viewers as a certain object's mimetic image is explored within the production of a specific narrative and signification.

Keywords: Visual symbol, visual metaphor, visual metonymy, online news, Croatia, Slovenia, migration.
\end{abstract}

\section{Introduction: The Visual Presentation of Migration in the Media}

This article focuses on the visualization of migrants and migration in online news to examine how metonymic, metaphorical, and symbolic images help construct narratives of migration. We take into account two transit countries and consider the Slovenian (rtvslo.si) and Croatian (hrt.hr) public broadcasters' online news during the migration situation in the fall of 2015. We concentrate on photos in which the phenomena of migration are portrayed in a way that excludes the representation of migrants. We use the term subjectless images to refer to this phenomenon. In our opinion, these images, which are characterized by "symbolic absences," carry an ideological meaning, and to our knowledge this has not been studied to date. We assume that this analytical choice will lead to some findings that go beyond the state of the art and provide 
insight into what we believe is, at least in the Croatian and Slovenian context, a new trend of presenting migrants worth examining.

Media images embedded in articles on migration, or appearing in isolation and in multimodal texts, produce a certain narrative alone or in combination with other semiotic means. Images may represent migrants in various ways: for example, as individuals or group members, as people in need of help, as a humanitarian challenge, as threats to sovereignty and security, or as criminals. Recent research on visual representations (often combined with a study of verbal representation) by and large reports visual strategies that contribute to negative presentations of migrants: visual presentations mainly indicate racism, criminalization, and various aspects of negative othering of migrants (see Martínez Lirola [2008, 2014, 2017, 2016]; Fernández and Martínez Lirola [2012] for the Spanish context; Batziou [2011] for Greece; Banks [2012] for the UK; Özcan [2013] for Germany; and Bleiker et al. [2013] for Australia). However, individual recent studies point to more varied visual presentations of migrants: for instance, Ibrahim and Howarth (2015) and Giannakopoulos (2016) concentrate on migrants' suffering and trauma, whereas Lenette and Miskovic (2016) examine refugee deaths, recognizing the potential of images to influence migration policies. Lenette and Cleland (2016) focus on the suffering of migrant children, and Permyakova and Antineskul (2016) determine that the images appearing in the Russian and French print media suggest not only the rejection of migrants by host societies, but also tolerance.

Although visual metaphors and symbols, and especially metonymy, are pervasive in press photography related to the representation of the recent migrant situation, they have been either rarely or only indirectly addressed. Among the few studies focusing on metonymies in media photography is one by Catalano and Waugh (2013): even though the authors analyze crime reports and only scarcely deal with migration, in the framework of Critical Discourse Analysis they nevertheless point toward the ideological potential of metonymies (an aspect extremely relevant to our analysis) such as DEFINING PROPERTY FOR PERSON and BODY PART FOR ACTION. Sindoni (2016) does not explicitly discuss visual metonymies and metaphors, but considers a relevant aspect: single instances of dark photographs and very long shots in which people are depersonalized. Visual metaphor and metonymy have been addressed in a few accounts of a different genre: cartoons thematizing migration. Domínguez, Pineda, and Mateu (2014) analyze the Spanish press between 2006 and 2012, exploring the symbolic role of boats, in addition to metaphors and 
metonymies. Some of the findings are applicable to the genre of press photography. Baek (2016) identifies five source domains for metaphorical conceptualizations of the Syrian refugee crisis: flood, war, sports, burden, and disaster, all of which are present in European political cartoons (see also Özdemir and Özdemir [2017], who analyze similar data and, among other topics, cover metaphors).

The presentation of migrants in images is always aimed at addressing audiences. Chouliaraki and Blaagaard $(2013,254)$ argue that images exert a performative power on the reality represented, simultaneously constructing it in meaning. Image presentations not only depict the world, but they also evoke emotions and visions of how the world might or should be. Therefore, images have a lot to do with moving readers and shaping readers' impressions and feelings about certain events (Zelizer 2010). More specifically, the visual presentation of migrants contributes to the emergence of collective sensibilities that either prevent or promote cultures of hospitality (Bleiker et al. 2013, 412). Kjeldsen (2017) addresses the argumentative potential of press photographs, concentrating on the photographs of Alan Kurdi that were widely shared and appropriated, and shows that photographs are not only used to contest meanings and values, but also to claim and make an argument.

This study is structured as follows. Section 2 gives some background to the 2015 migration situation in Slovenia and Croatia; that is, the political context specific to these two transit countries. Section 3 then provides a description of the sample and sources, and a brief quantitative overview

of the categories that emerged from the data collected. Section 4, which is complementary to Section 3, is concerned with a theoretical approach to metonymy, metaphors, and symbols; that is, the three visual tools we focus on in the analytical part (Section 5). In Section 5, we develop our multimodal analysis in detail by concentrating on four selected cases, followed by a conclusion (Section 6).

\section{Context: Slovenia and Croatia as Part of the Balkan Route}

In order to reach their target destinations in western and northern Europe, migrants ${ }^{\mathrm{i}}$ from Syria, Afghanistan, Iraq, Pakistan, and other countries traveled on the Balkan route initially extending across Turkey, Greece, Macedonia, Serbia, Bulgaria, and Hungary. It is estimated that during 2015 around 764,000 migrants passed through the countries on the Balkan route (Frontex, cited in Jakešević and Tatalović 2016, 1255). However, this route was shut off on September 15th, 
when Hungary decided to close its borders and seal them with razor wire. Consequently, migrants hoping to enter Hungary by transiting Serbia were suddenly redirected to Croatia and from there continued their journey through Slovenia, ${ }^{\text {ii }}$ the entry point to the Schengen area. The first large groups of migrants entered Croatia on September 16th. ${ }^{\text {ii }}$ Unable to manage the sudden migrant situation, Croatia temporarily closed all of its border crossings with Serbia while at the same time trying to promptly transport migrants to the Slovenian border. On September 17th, approximately two hundred migrants coming from Croatia by train crossed the Slovenian border. The Slovenian government decided to deploy its police force in full riot gear, thus aiming to protect the Schengen border. Migrants were detained at alien centers or in monitored, fenced-off areas along the Slovenian-Croatian border. Due to miscommunication between the two countries, migrants often became trapped between the two borders, waiting without food, water, and shelter for many hours to undergo the registration process in Slovenia (Amnesty International 2015; Ladić and Vučko 2016). In both countries, a government headquarters was established and reception centers were set up as soon as the migrants started to enter the countries. Throughout the fall of 2015, both countries dealt with logistical issues concerning the admission, registration, and transportation of migrants, as well as the provision of basic humanitarian aid, shelter, and medical assistance. The police, humanitarian organizations, civil protection, and later on even the military were engaged in providing humanitarian aid, helping with logistics, and assessing security. Although both countries have the relevant legislative framework in place for asylum, they both remained transit corridors (Šelo Šabić and Borić 2016; Vezovnik 2018; Jakešević and Tatalović 2016).

In November 2015, the Slovenian decision to increase security measures was followed by the Slovenian government's decision to install razor wire along the Slovenian-Croatian land border. This decision led Croatia to send multiple protest notes to Slovenia. During the same period, Slovenia demanded that Croatia readmit migrants coming from non-warzones. These events were followed by political disputes between the two countries. After November 2015, the number of migrants crossing Croatia and Slovenia drastically diminished. In March 2016, when an agreement was reached between the members of the European Council and the Turkish government, the Balkan route closed almost completely.

In both countries, the media, including the public broadcasters focused on here, closely followed the migration situation. 


\section{Sources, Method, and Sample}

First, we collected and analyzed 691 articles (mainly news items) altogether, using the search functions at rtvslo.si and hrt.hr. ${ }^{\text {iv }}$ In all of them, migration and migrants were the main topic or one of the main topics. After obtaining a list of articles using the sorting method of relevance (versus chronological order), we first determined the rubric in which the articles appeared, and we then read the headlines, subheads, and leads of all potentially relevant articles to identify the main topic(s). In some cases, when we were in doubt, we read entire articles. Out of the selected articles, 288 articles were published by rtvslo.si, ${ }^{\mathrm{V}}$ a news website of the public broadcaster RadioTelevision Slovenia, and 403 articles by hrt.hr, ${ }^{\mathrm{vi}}$ a news website of the public broadcaster Croatian Radio and Television. The articles were published between September 15th, 2015, when the Balkan route was redirected to Croatia and Slovenia, and November 15th, when significantly fewer migrants entered Slovenia and Croatia in comparison to September and October 2015, and the number of articles related to migration started to diminish. The data collected include articles containing the keywords immigration, migration, refugees, migrant, immigrant (Sln. imigracija, migrant, immigrant, migracija, begunci, prebežniki, and Cro. migracija, migranti, izbjeglice). ${ }^{\mathrm{vii}}$ The initial visual data consisted of 741 images collected from rtvslo.si and 1,347 images collected from hrt.hr. Hrt.hr is therefore more visual than rtvslo.si. For this reason, although the total number of articles published in the period analyzed is higher in hrt.hr, the total number of words in hrt.hr $(127,000)$ is lower in comparison to rtvslo.si $(134,000)$. The analysis was conducted in three stages, corresponding to the three rounds of data coding. All of the data were first coded for their content (e.g. active/passive migrants, politicians, security forces, etc.), and during that process images without subjects emerged as a significant category. Although subjectless images did not dominate the data quantitatively (their share in rtvslo.si is $27.3 \%$, and in hrt.hr 20.7\%), we believe that it is important to explore these images in which visual metonymies, metaphors, or symbols were mainly created by objects (e.g. fences, garbage, razor wire, vehicles, and border signs) still representing the phenomenon of migration, and migrants as its agents.

Therefore, during the second stage of the analysis we identified all subjectless images and coded them manually. Both authors agreed on the codes. We coded part of the material (around $10 \%$ ) together to establish a preliminary agreement. We first coded the rest separately. Later, we exchanged the coded material, checking each other's codes. We discussed the images about which there was some uncertainty or disagreement (3\%) before we finally agreed on the codes. 
Subjectless images were defined as images in which migrants are (almost) absent. Two subjectless sub-categories emerged:

(1) Images in which migrants are formally present but are hardly visible and distinguishable, backgrounded, or blurred. Such cases also include images in which migrants appeared as an undistinguishable mass of people photographed from a large distance (e.g. from above), those in which migrants are photographed from behind, and those in which migrants' faces were covered or obscured: for instance, when faces were blurred in post-production or out of focus, or covered by clothes.

(2) Images in which no subjects are present at all, or in which only certain body parts appear (feet, hands, etc., but not faces or the entire body).

In the second stage, a thematic analysis was conducted. All subjectless images appearing at the top of the article in the case of hrt.hr and those appearing in the body of the article in the case of rtvslo.si were taken into consideration and coded in order to determine which content appeared most frequently. The images were coded and included in one or two of the categories that emerged in the second round of the coding process. These categories relate to the explicit image content: what is shown in the image (e.g. borders, means of transportation, etc.). We also defined the most emphasized ${ }^{\text {viii }}$ element in the images if more than one content category was present. Some of the images showed more than one category (e.g. humanitarian help and active police agents), and none of these were clearly emphasized: similar cases were coded twice. This was the case with approximately $10 \%$ of the images. In this first stage of thematic analysis, the content-related categories - listed in Table 1 below - emerged. For a more detailed overview of content categories and related quantifications, see Table 1 below.

\section{[Table 1 near here]}

Although subjects might be the most newsworthy material, in the data analyzed subjectless images turned out to be important due to their considerable number and content meaningfulness. Therefore, in the third stage of the analysis, the same data consisting of 481 subjectless images were coded again: this time according to whether they represented visual metonymies, metaphors, or symbols. Also in this case, $10 \%$ of images were coded twice. All in all, 59\% of all images were categorized as metonymies, $34 \%$ as symbols, and 6\% as metaphors (see Table 2). 
[Table 2 near here]

The aim of the second and third round of coding was to develop a typology of data in terms of content; that is, to determine what is present in the image and whether an image works as a visual metonymy, a symbol, or a metaphor. In the multimodal analysis that follows in Section 5, we present a detailed analysis of what we identified as four representative samples of selected content-related categories. We only considered images appertaining to categories with a higher percentage of coded units, ideally those simultaneously belonging to two categories. More precisely, we considered images falling into at least one of the top seven (out of fifteen) categories; that is, categories 1.3, 1.2, 2.2, 2.4, 1.8, 1.5, and 1.6 (see Table 1). When selecting the representative samples presented in Section 5, we selected images showing a symbol, metaphor, or metonymy - crucial meaning-creating devices in our data.

However, before turning to the selected images in Section 5, we provide a brief theoretical background to visual metonymy, metaphor, and symbolism, which these subjectless images relate to.

\section{Theoretical Framework}

\section{Visual Metonymy, Metaphor, and Visual Symbolism}

In line with cognitive approaches to metonymy and metaphor, we assume that metonymic and metaphorical thinking can be traced in visual and multimodal communication (see Fahlenbrach [2016]; Forceville [2009]; Forceville and Urios-Aparisi [2009]). These recent approaches to visual metonymy and metaphor are influenced by Cognitive Metaphor Theory (Lakoff and Johnson 1980), which explains metaphor and metonymy as phenomena of thought. In metaphor, a relation that can be formalized as $X$ as $Y$, two entities belonging to two different conceptual domains are brought into a relation, whereas in metonymy (an $X$ for $Y$ relation) two entities belonging to the same conceptual domain are brought into a relation. ${ }^{\text {ix }}$ Visual metonymy is the most important feature of our data, whereas some less frequent visuals can be regarded as metaphorical. Visual symbolism (often based on a metonymic reference) is also a relevant category because a number of images in our data explicitly present official symbols, objects with a symbolic value, or "symbols-in-making" (see Section 5). 
In photography, metonymy can be seen as governing two general principles of how this mode represent its object(s) (see Huxford [2001]; Forceville [2009]). These metonymic principles are of two types. In (A), a photo (as an object) stands for what it represents (e.g. a photo of a statue stands for the statue: a concrete object located in the park). In (B), the object in an image (e.g. a statue) is part of a larger whole (e.g. the statue's larger surroundings, a park). Photos always show only a fragment of a larger whole. Accordingly, metonymy is an omnipresent phenomenon inherent in photography, and in visuals as such, because these are never exact replications of reality, but only its partial representations (see Feng [2017, 442]). However, considering all photos as metonymies does not offer any analytical value. Some further "levels" of metonymic expression in photos are context-dependent. For example, a statue in a photo stands for a war or battle; this would be $(\mathrm{C})$. Whereas (A) does not relate to communicative intentions, and (B) sometimes relates to them, $(\mathrm{C})$ is likely to be coupled with a particular communicative intention. For this reason, we concentrate on Categories B and C below.

Because less-than-total presentations of objects and persons are a standard practice in photography (see e.g. Caple [2013]), in analyzing visual and multimodal metonymy (the former is realized in visual mode only, and the later in a combination of modes; for example, verbal and pictorial mode; see Forceville [2009]), communicative intentions underpinning choices are important. Photographers make a choice when using a closeup or another shot. Likewise, an editor at a later point makes a choice when deciding to incorporate a closeup photo instead of a long-shot photo in a multimodal "text." Photographers and editors also optimize the communicative events they produce or influence in terms of relevance (Sperber and Wilson 1995).

Even if some metonymies (e.g. feet for certain actions, typically moving) belong to the set of standard (visual) synecdoches, they still deserve special attention because of their function in a particular context.

Definitions of symbols emphasize that they "stand for something else" (e.g. Merriam Webster online). Many symbols are material, visible objects, but can also be immaterial. Forceville $(2009,71)$ indicates that symbols are metonymically motivated. This is the case with some objects that function as symbols of towns or countries in many different contexts (e.g. the Eiffel Tower as a symbol of Paris and France). Womack (2005, 5-6) indicates that, although the meaning of symbols is generally arbitrary, the relation between some symbols and their referents is metonymic (e.g. the cross that evokes Christ's suffering and Christianity). However, the link between some 
other symbols and their referents is metaphorical, based on perceived similarity (e.g. the characteristics ascribed to eagles - strength, power, and vitality - are projected onto a state if the eagle is the symbol of that state).

In our data, individual images can be interpreted as visual metaphors: in them, the source and target domains are expressed in the same, visual mode (see Forceville [1996]). In previous research, there are two dominant approaches to this phenomenon: one strand of research - for instance, Carroll $(1996,10)$ - concentrates only on surface realizations and formal characteristics of objects shown, assuming that visual metaphors imply visual fusion and/or amalgamated structures in which two domains of experience are brought together: for instance, the face of a politician can be combined with the body of an animal, which would suggest the metaphor A PERSON/POLITICIAN IS AN ANIMAL. Forceville (1996) also focuses on form and surface realizations, understanding pictorial metaphor as the replacement of an expected visual element with an unexpected one. Visual fusions and amalgamated structures are extremely genre-specific and very rare in the media.

Visual metaphors are frequently used and can easily be identified in (political) cartoons, in which elements from two distinct domains are intentionally fused. Such metaphors are purposeful creations; they are at times visual only, and at other times both visual and verbal, or multimodal $(\text { see Forceville }[2016,20])^{\mathrm{x}}$ if supported by captions or words included in the image. Similar structures are difficult to imagine in the naturally occurring settings that newspaper photos as a rule relate to.

Another strand (see El Refaie [2003]) suggests that any visual depiction can be an instance of metaphor if its use is intended to provoke a metaphorical thought. This implies that certain elements and their combination in a photo, or a combination of some elements in the photo and some elements in the verbal part of a message, can indicate an underlying metaphorical concept; for instance, LIFE IS A JOURNEY. We follow this view on metaphors that has not received much attention to date: it implies that it is misleading to say that something "is" a metaphor. Rather, it is better to refer to "construing a metaphor" or "interpreting something as a metaphor" (Forceville 2016, 25). Importantly, a visual depiction can trigger a metaphorical thought without any intention by image producers or editors, and it should also qualify as a visual metaphor in that case.

In our data, metonymies (the prevailing category), metaphors, and symbols are relevant as a communicative choice. For instance, the source concept (e.g. a foot) is chosen, rather than the 
entire entity it refers to (the target concept, the body). A single source concept can refer to different targets simultaneously, or to different targets in different contexts; the concept the source refers to can be of varying complexity. We are interested in metonymies, metaphors, and symbols that are relevant as communicative choices and might produce some effects: for instance, changing salience and viewpoint, evaluation, and producing specific connotations that explicit references to target concepts would not produce. Moreover, because metonymies, metaphors, and symbols highlight some aspects of an entity or situation and downplay others, they can be a useful device in presenting a particular view by a discourse producer, or in influencing others by drawing their attention to a particular aspect of a phenomenon (and hiding others; see Machin and Mayr [2012]). Metaphors and metonymies relate to expressing and hiding ideological views (see Goatly [2007]), which we address in the next section.

\section{Ideological Implications}

The ideological function and significance of metaphor has been highlighted several times (for an overview, see Machin and Mayr [2012]; Underhill [2011]; Goatly [2007]). Which metaphors become accepted can have implications not only for how we think about and understand the world, but also for how we act, what institutions we build, and how we organize our societies (Machin and Mayr 2012, 164). Metaphors have hidden ideological loadings due to the way they can conceal and shape understandings while at the same time giving the impression that they reveal them. They are therefore a (visual) way of hiding the underlying power relations. According to Littlemore $(2015,101)$, metonymy similarly "plays a key role in the development of patterns of reasoning"; the same is true for symbols. The three devices can be employed in creating specific worldviews that may seem "natural," but nevertheless relate to ideology, persuasion, and positive and negative evaluation when, for example, used by politicians and journalists to highlight the positive characteristics of "in-groups" (see Van Dijk [1998]). On the other hand, the ideological potential of metonymies lies in their ability to reduce the complexity of an event, blur or hide responsibilities, downplay the effect of some actions, and emphasize some aspects of a situation while hiding all the others. For example, items metonymically standing for humanitarian help in our data emphasize a single aspect of the migration situation: metonymy reduces the receivers of humanitarian help to a single aspect only, and contributes to representing them as dependent and powerless on the one hand, and, on the other, it focuses on a single action (by the state or an 
organization), downplaying others. It thus contributes to a one-sided representation. Some other metonymic images - for instance, those showing improvised beds and toilets in detention facilities - reduce the complex cluster of needs of individuals and groups (and thus their identity) to two basic needs. Metaphor, metonymy, and other cognitive and rhetorical tools therefore provide excellent linguistic and visual resources for those that wish to replace concrete processes, identities, and settings with abstractions (Machin and Mayr 2012, 164).

\section{The Meaning of Subjectless Images}

This article shows how symbols, metaphors, and metonymies work in subjectless images. Therefore, the paradox addressed in this analysis is one of absent subjects being represented by symbolic, metaphorical, and metonymic objects. In other words, what is worth exploring is the non-overt meaning, the invisibility and un-representability of migrants that is expressed via symbolic, metaphorical, and metonymic objects. The cases presented are therefore the systems of identification that replace subjects with objects while subjects' voices and faces remain unseen and unheard. Therefore, what needs to be discussed now is the role and potential meaning of migrants as subjects and migration as a phenomenon represented by objects in images as well as the connotative level and the ideological operation behind such presentations.

News photos usually present human subjects, which play a central role in journalism according to Hall (1981). People - human subjects - "are par excellence the content of news and feature photographs" (Hall 1981, 237). According to Hall (1981, 229), closeups of subjects' faces are used to allow the viewer to read the most expressive parts of the body; that is, the eyes and the face. For social and psychological studies, studies in social semiotics, and multimodal analysis alike, closeups (showing people's faces) are the type of images most likely to evoke compassion in viewers (see Kress and van Leeuwen [1996, 2001]; van Leeuwen [2008]). This particularly applies to photos of people's faces in “demand images" (Kress and van Leeuwen 2001, 122, 126), in which the persons shown look directly at viewers, and this, along with the frontal angle, medium vertical angle, and intimate distance relates to strong viewer involvement with these images. ${ }^{\text {xi }}$

In contrast to images of individuals, images of groups tend to create emotional distance between viewers and the subjects in the images: social semioticians' assumption (see van Leeuwen [2008]) is that camera shots indicate social distance: a closeup shot makes it possible to establish an imaginary intimate relationship between viewers and the participants shown, a mid-shot enacts 
a social relationship, and a long shot enacts an impersonal relationship between viewers and the participants shown. Similarly, phenomenological studies determine that the way we look at objects is not the same as when we look at subjects. When looking at subjects, viewers might identify with them, whereas looking at objects implies detachment and no emotional investment (Jonas 1954).

Hence, as Barthes (1977) points out, objects are inducers of associations of ideas, especially when they adopt the role of symbols, metaphors, and metonymies. In each case, objects are elements of signification and possessors of meanings (Barthes 1977, 201-202). In addition, looking at an object is a major source of knowledge, not just about the thing itself shown in an image, but about the larger process of generating memories, associations, and fantasies. Objects are triggers of chains of ideas. It is reasonable to assume that viewers see something beyond physical objects. Objects shown in images are artefacts; they were "made" knowingly at a particular time and place. At the same time, they are texts requiring interpretation (Jordanova 1989).

In what follows, we analyze four representative images. These images are parts of four multimodal texts, and the interpretation of their meaning relates to these texts. We believe that an interpretative analysis of the four representative images will allow us to understand visuals on migration in a much more complex and detailed way than the use of a quantitative analysis only. For reasons of space, we concentrate exclusively on images, but we provide some remarks on the images' immediate context. ${ }^{\text {xii }}$

\section{Analysis of Subjectless Images}

An image showing specific objects related to people belonging to a certain culture or ethnicity is ethnographic in the sense that it aims to describe specific nations, groups of people, and/or races with their customs, habits, and points of difference (Lidchi 1997, 160). Along these lines, the first two images we explore - the first showing waste left on empty railroad tracks (see Figure 1) and the second showing a toy caught in razor wire (see Figure 2) - have an ethnographic value: it lies in the paradigmatic characteristics of ethnography collecting and documenting objects believed to be novel, curious, exotic, primitive, savage, and so on. In other words, the focus of Western ethnography is objects believed to belong to the "other"; that is, non-European or nonWestern civilizations (Lidchi 1997, 161). However, the journalistic documentation of these ethnographic objects belonging to the "other" goes beyond mere documentation of reality. As Hall 
(1981) puts it, journalistic photos are always full of ideological meanings. As Figure 1 demonstrates, images often create cultural distinctions.

Figure 1: Waste on railway [near here]

Source: $\quad$ http://vijesti.hrt.hr/299246/u-hrvatsku-uslo-vise-od-11-000-migranata-zatvoreno-7granicnih-prijelaza-prema-srbiji

Negative news stories about ungrateful migrants leaving waste behind are very meaningful, and some previous analyses have already pointed out the ideological charge of such news stories in the Slovenian tabloid press (see Vezovnik [2017]). However, as Figure 1 shows, waste can also be a relevant topic to hard news. The image appeared at the top of a very short article describing the calm in a Croatian town after migrants left. The image showing waste on empty railroad tracks was coded into two content-related categories - i.e. 1.5 and 1.6 and contains two metonymies. The first one is represented by the tracks, which stand for the migrants' journey. The second one is represented by waste appearing as a metonymy in which an object (waste) is closely related to the subject (migrant) and the former works as a substitution for the latter. The two metonymic operations make it possible to represent the subjects/migrants and their activity through their absence. It is obvious that migrants are not in the image because they have already left on trains. Hence, what is used to represent them is the waste they left behind. In this image, part of migrants' behavior or practice (discarding waste) becomes the most significant signifier for migrants as a group of people, perhaps even as a social category.

Because the image documenting waste left on the tracks works as a document of migrants' past actions, there is an obvious dimension of time embedded in it. According to Barthes (1982), photography has a peculiar capacity to represent the past in the present. He (ibid., 95) points out that the paradox of photography consists in the punctum, a category related to both time and detail. According to him, photographs always display things and people that have been there but will disappear at some point. People in images may die, waste left on the rail tracks will be eventually removed. Images, therefore, present us something that is in the past. As such, photos bring up a confusion between concepts of what Barthes names "real" and "live." As Barthes $(1982,79)$ points out, 
“/../ by attesting that the object has been real, the photograph surreptitiously induces belief that the object is alive, because of that delusion which makes us attribute to Reality an absolutely superior, somehow eternal value; but by shifting this reality to the past ('thishas-been'), the photograph suggests that it is already dead"

or gone in the case of waste. By looking at Figure 1, time might be perceived by the viewer in two ways. First, by not showing the people that discarded the waste, the photo invites the reader to logically infer that migrants are not in the image because they have already left the scene. The only way to represent migrants is therefore to show the objects they have left behind. In this sense, the image documents some action that happened in the past. Second, a time perspective is implied by the perspective from which the image was taken. The viewer of the image is supposedly looking in the direction of the train that left and is now positioned in between the dirty tracks. The migrants that left the trash behind are now absent, and the waste is the only evidence of their past visit. Moreover, waste is also something that "we" are or have been left to deal with in the future, or at least after the image was taken and after migrants left. Emphasis placed on the waste that appears as the central object in the image might imply migrants' carelessness and bad manners. The centrality of the waste lying around in a chaotic way also stands in contrast to the order that the image otherwise establishes through its ideal composition: the horizontal straight lines of the tracks and platform coming together at a point on the horizon. This duality potentially attracts the viewer in terms of punctum related to detail (Barthes 1982, 27, 42, 45) because it contains two discontinuous, heterogeneous, and contrasting elements in that they do not belong to the same world.

However, objects such as waste not only appertain to us or others; they are constitutive of social relations among groups (see Mlekuž [2011]). They are crucial for understanding and constituting the meaning of "us" and the "other." Our Western idea of dirt is compounded of two things: concern for hygiene and respect for conventions (Douglas 1984, 7). The waste in the image challenges them both. Waste is an object that clearly divides the Western and Eastern cultural and civilizational ethos, leading to more general associations of cultural difference between "us" and "them." The visual duality of waste representing dirt and chaos versus the order expressed by the composition of the photo stimulates readers to align themselves with or against certain groups or ideas (Machin and Mayr 2012, 84). This is reinforced by putting the viewer in a position in which they are left alone with the problem of waste and creating structural contradictions that van Dijk 
(1998) calls "ideological squaring" - here mostly evident in negative presentation of the "other." Douglas $(1984,37)$ shows that objects or ideas that confuse or contradict cherished classifications provoke hostile behavior that condemns "them." She calls these confusing or contradictory elements ambiguous, anomalous, and indefinable, "uncomfortable facts, which refuse to be fitted in," which, she claims, "we find ourselves ignoring or distorting so that they do not disturb these established assumptions." The migrants' practices are indeed constructed as such contradictory elements. Waste appears to be out of place (thrown onto railroad tracks). This makes the meaning of waste grow through a simple metonymy: it becomes more of a symbol for migrants as disturbing, polluting, and dirty elements unwanted in an (ethnically) clean environment. As Douglas would put it, migrants appear to be culturally different precisely because their culture and practices are constructed in a way that morally contradicts "our" codes, habits, and character. The migrant "others" with their habits and practices such as discarding waste become a potential cultural threat to the majority population because they threaten "our" purity and homogeneity by barbarically invading “our" space. ${ }^{\text {xiii }}$

A duality is also present in the second image, coded in the content related categories as 1.3 and 1.5 (Figure 2): the duality of razor wire and a toy. The article reports on the Hungarian border closure, and beneath the image we find a simple statement saying when the border was closed and when it reopened. In the background on the image we find a tall wall, a tree, and a border sign in Hungarian. In both Figures 1 and 2, such duality rooted in details and working as punctum potentially attracts the viewer in the same way because it contains discontinuous, heterogeneous, and contrasting elements in that they do not belong to the same world.

Figure 2: Toy on razor wire [near here]

Source: http://www.rtvslo.si/svet/v-avstrijo-v-dnevu-in-pol-vstopilo-22-tisocprebeznikov/374444

One part of the image presenting the toy is metonymic: the toy presumably belonged to a migrant child, and thus the metonymic relation is based on the possessor-possessed relationship. In the metonymic interpretation, the toy stands for migrant children. ${ }^{\text {xiv }}$ The other part presenting the razor wire is perhaps symbolic because the razor wire could symbolize Fortress Europe and its securitization policy during the refugee situation. Like the first one, Figure 2 also represents a clash 
of two opposing meanings. The first is represented by the child's toy connoting innocence and carelessness (of a child's spirit), freedom (of playing), softness (plush material), and so on. The second, represented by the razor wire, connotes harm, aggression, sharpness, and militarization to some viewers, but perhaps also security and safety to others. The toy standing for the migrant child is entangled in the razor wire and hurt by it. This suggests that the toy may be seen as "collateral damage" of security measures. Therefore, the image may suggest critical understandings of security measures adopted by the EU countries. ${ }^{\mathrm{xv}}$ It would be less likely to read the image as supporting such security measures. The rationale behind the image showing a toy instead of a migrant or a migrant child is perhaps to gloss over the migrant child's body when stopped by razor wire. Moreover, the image might even seem ironic because the security measure intended to fight against a potential threat representing a security risk to the European population is embodied in a harmless teddy bear, standing for a harmless migrant child. In addition, this image is perhaps the most complex one because it visually presents a "clash" of two contrasting approaches to the migration situation: humanization and victimization (approaching it in human terms) on the one hand, and securitization on the other.

In addition to those showing objects, images showing migrants' body parts were also frequently featured (see Figure 3).

Figure 3: Muddy feet [near here]

Source: http://www.hrt.hr/301079/vijesti/u-hrvatsku-uslo-vise-od-87-tisuca-izbjeglica

Figure 3 was coded in the content-related categories as 2.4 and 2.2 and is a typical instance of visual metonymy. It is part of a series of five images (which are themselves part of a multimodal $^{\mathrm{xvi}}$ text $)^{\mathrm{xvii}}$ that show tents and migrants standing in raincoats on the wet ground. The image shows shoes and part of the legs, standing for a human body. The image also has some symbolic and metaphorical aspects (see below). A further metonymic relation signalized by this motif is walking: in this conventional relation, certain body parts are associated with activities they often perform: for instance, hands with physical labor, feet with walking, and the head with thinking. The face is metonymically the most salient part of the human body - it is used for identifying individuals (e.g. it is part of official identification documents). The part of the human body occupies a smaller part of the image: the largest part is mud. The shoes are covered with mud, as are the visible parts of the trousers. 
Although images showing only parts of human bodies are not very frequent in our data, this image with its meaning potential is nevertheless typical as an illustration of the tendency observable in many other visual and verbal presentations of migrants ${ }^{\mathrm{xviii}}$ that emphasize movement and a journey (e.g. many photos show trains and busses, which metonymically stand for migrants' journey). The emphasis on a journey relates to social reality because Slovenia and Croatia were transit countries on the migration route.

Movement is a basic human physical activity: basic in the sense that it pertains to all humans in their everyday life. However, it does not relate to the complex character of an individual's identity. Humans are formally active when consciously moving, but this material process does not relate to typical agency. Thus, in this image, as in many others related to the journey scenario, migrants are reduced to an everyday activity. These activities are nontransactive actions including one participant (or one group of participants) only; they do not affect others or the world and do not require power, like transactive actions do (see van Leeuwen [2008, 60]). ${ }^{\text {ix }}$

The mud as another prominent motif metonymically relates to bad weather and rain, thus denoting difficulties migrants experience on their journey. The specific position of the feet in the mud additionally suggests that the person is experiencing difficulty moving at the particular moment: the mud indicates an obstacle. At the connotative level, mud is related to negative aspects; this is reflected in fixed expressions containing mud in many languages. Mud is associated with a variety of negative phenomena, such as dirtiness, immorality, poor living conditions, and low status; for this reason, it also can be conceived of as a symbol for these phenomena. Another association is danger (e.g. related to mudflows and situations in which somebody or something gets stuck in the mud). These denotative and connotative dimensions of mud can potentially be related to migration, and the image can occasion certain metaphorical thoughts in some viewers, ${ }^{\mathrm{xx}}$ who may, for instance, establish metaphorical mappings between the domains of mud (and being stuck in it) with the migration situation, ${ }^{x x i}$ whereby migrants' struggle and suffering are foregrounded. Or they may remain at the more literal visual level and relate migration to concrete features of mud that they have experience with (e.g. mess, dirtiness, etc.).

The perspective from which the viewers are looking at the feet is top-down: viewers do not see a person with a recognizable facial expression with whom they could potentially sympathize. A migrant is portrayed as a victim of the journey and its circumstances (not as a victim of the system, as in the toy in the razor wire image). The metonymical presentation here is an ideological 
operation: the idea behind the photographer's decision to show only the feet is to take away human individuality (see Meadows [2006]) and replace it with an emphasis on "objective" circumstances that make the journey of deindividuated persons difficult.

Figure 4 : Migrant caravan [near here]

Source: http://www.rtvslo.si/slovenija/ne-more-vsak-na-terenu-poceti-kar-ga-je-volja/377195

Figure 4 appertains to the content-related category 2.2. To us, this is an example of an image that is likely to occasion metaphorical thought (El Refaie 2003). We claim that some viewers are likely to construe a metaphor in similar cases; specifically, the metaphor MIGRATION IS MOVING WATER / A RIVER. The metaphor's source domain is water, and the target domain is the migration situation. ${ }^{x x i i}$ This image was reproduced more than once, and it was found in both hrt.hr and rtvslo.si. The image is part of a multimodal text consisting of verbal elements and a few images with captions. ${ }^{\text {xiii }}$ The form of the moving group of people (the object depicted) resembles an object from a different domain, and some viewers can infer a conceptual link between two domains. The visual form beginning in the upper left corner of the image and ending in the lower right corner resembles a river. Furthermore, in this image, the journey scenario is thematized, pertaining to the fact that the two countries were transit countries on migrants' journey. The extreme high angle makes the different colors of this river-like form somewhat uniform: it is blueish and rather dark, running between the much lighter fields with an orderly geometrical form. The dark "river" clearly contrasts with the green and beige of the fields, which look idyllic. Almost resembling a painting, the image is somewhat aestheticized. The extreme high-angle shot and the bird's-eye view, often related to authority and surveillance, make it possible to present the subjects as an undistinguishable mass. The shot presents the point of view of a distant observer. By increasing the importance of the broader space around them, it decreases the importance of the subjects in the image, presenting them as a mass and a strong stream.

Some viewers will argue that this photo depicts a moving group of people (this is explicit in the verbal context), that is, one domain only, and thus cannot be metaphorical. However, this representation is interpreted as a visual metaphor by some viewers, including us, because of resemblance: the form and color of what is actually shown resembles something else. As indicated, with non-verbal metaphors, metaphorical construals and interpretations are a may, not a must. 
At first glance, this image represents a view on migrants that is clearly in contrast with metonymic images showing just parts of (individual) people's bodies: it shows a large number of people moving. Furthermore, the image illustrates a frequent presentation pattern of migration in which large groups of people are visually presented, and no individuals or individual traits can be identified. This is in accordance with verbal presentations mentioning large numbers. In Figure 4, the extreme high angle makes it impossible to identify any individuals. The image shows people moving, but at the same time it is not possible to really see them; bodies are present and not present, they cannot be seen, what can be seen is "dots" only. The high camera angle constrains the possibility of conceptualizing the moving persons as subjects. The distance from which the migrants are photographed does not allow any possibility of a deeper engagement or interaction. Viewers cannot really conceptualize the people depicted as individuals, as humans with distinct, complex identities. The visual form in Figure 4 indicates absolute anonymization and desubjectivation. Still, paradoxically, the caption and other verbal and visual elements of the multimodal text this image is part of signal that people - migrants - are actually represented.

Similar visual presentations facilitate the activation of the metaphor MIGRATION IS MOVING WATER / A RIVER. Verbal elements that do the same are (in)flow, stream, rivers, and waves (of people). Quantifying migrants in terms of moving water metaphors has been noticed in various national discourses (see Baker et al. [2008]; Dervinytė [2009]; Catalano [2016]; Vezovnik [2018]). However, metaphors as such (including moving water metaphors) are often neutral: they acquire positive or negative evaluative force in their context. ${ }^{\text {xiv }}$ In the period analyzed, the strong emphasis of media presentations was indeed on large numbers (there were numerous reports thematizing thousands of people overflowing small villages) and on security. In this particular context, many positive or neutral cultural connotations related to rivers were backgrounded, and the topos of danger was emphasized - rivers are very long and difficult to control, and they can overflow fields and settlements. The flow of water can change the idyllic landscape.

\section{Conclusion}

The visuals discussed in this analysis - subjectless images - are only part of the broader visual material employed in the two sources analyzed. They are nevertheless an important part, its importance being related to their ambiguity and openness to different interpretations, which we indicated in the preceding sections. Whereas some viewers may relate the negatively evaluative 
metaphor MIGRANTS ARE MUD to one of the images discussed (Figure 3), some others opt for a metonymic interpretation, relating it to obstacles and difficulties experienced by the migrants. Whereas the image in Figure 2 with its toy and razor wire may be interpreted by some viewers as emphasizing a strict security measure, other viewers may be concentrating on the toy and its position and will interpret it as a metonymy in which the migrant child is replaced by his or her toy, which becomes a symbol of suffering. The attitude of potential viewers is related not only to their background knowledge about the subject and the manner in which they read images, but also to the entire multimodal context. A step further in future analyses is to look at how exactly these images relate to their context (i.e. verbal elements and videos). This analysis has shown that some of the subjectless images are open to a much broader range of interpretations than verbal texts are, and in some cases these images "unite" a few rather different discourses.

In spite of the fact that the images analyzed may not be uniform in terms of content and potential reading, what they do have in common is precisely their ideological operation. We are referring to the fact that subjectless images represent subjects through objects by using visual metonymies, metaphors, and symbols.

In metonymic images in which metonymies relate to migrants' behavior or practice (constructed as negative; e.g. throwing waste), that practice becomes the main signifier for migrants, even a symbol. Thus, it may contribute to stigmatizing migrants as a group by, for example, constructing them as disturbing elements and potential cultural threats in an otherwise clean, neat environment. Other metonymic images (e.g. showing feet) reduce migrants' situation to "neutral" everyday activities (typically movement and journey) and hide the complex character of migrants' identity and their migratory experience. The metaphorical image in Figure 4 presents the point of view of very distant observers: the people in it are hardly recognizable and appear as colorful dots and rivers. By increasing the importance of the broader space around them, the shot decreases the importance of the represented subjects and represents them as a mass of intruders flooding "our" land, underpinning the idea of migration as a scarcely controlled phenomenon that needs to be monitored, controlled, and surveilled.

All these operations are ideological because migrants are placed in the Western sociopolitical order, in which they become victims, barbarians, invaders, and security threats. These ideological operations take away the convolutedness of migration and migratory subjects, depriving migrants not only of their right to speak (e.g., their voice) but also of their right to appear 
as essential human beings. The result creates the impression that migrants do not belong to the order of "us"; that is, humans. In Aristotelian terms, by taking away the most basic features of being human, the media deny the existence of migrants as both zoe and bios. In other words, the media background migrants' living/biological functions (zoe) as well as their political aim of freeing themselves (bios), which underlies migration processes. Moreover, denying the representation of "others" as humans symbolizes a step further from representing them as suffering desubjectivized victims (that at least acknowledge zoe), which the Western gaze can relate to. Chouliaraki (2012) and Vezovnik [2015] show how portraying "others" as victims often involves publishing images with clearly decodable pain and suffering that viewers can relate to, mainly because such representations involve suffering and impotence, but not active political actions. In subjectless images, migrants' emotions, agency, state of mind, and so on are not represented. This creates a further detachment of the viewer in relation to the subject portrayed. If the image of the victimized "other" fits the frame of "human rights" narratives adopted by the mainstream media well, then the subjectless images we explored represent a step further in denying migrants' subjectivity and their right to exist as biological bodies as well as political subjects. It is also worth emphasizing that, with these images, the only discourse that the two public broadcasters transfer to the public is that of mainstream politics, which is led by the rhetoric of threat and security. Although we all know that the media play an instrumental role in constructing "us" and "them," we have to take into account that the mainstream media, especially national broadcasters, rely heavily on political leaders' and migration experts' frames and produce few frames themselves (Watson, 2009, 21). However, understanding the role of the media solely as a mouthpiece for political elites ignores the importance of media agency in shaping hegemonic migration discourses. The media's inability to recognize the complexity of the interwoven factors and voices inherent in each migration situation should be addressed from here on -and we leave this task to whoever takes it up next.

\section{Notes}

\footnotetext{
${ }^{\mathrm{i}}$ We use the term migrant for all categories of people that crossed the Slovenian and Croatian borders in order to transit the countries or apply for asylum. Intentionally we did not categorize them according the popular distinction between refugees from unsafe countries (forced migration) and migrants from countries considered safe (economic migration).
} 
ii Slovenia and Croatia are both former Yugoslav countries, now EU members. Slovenia joined the EU and NATO in 2004 and the Schengen area in 2007. Croatia has been an EU member since 2013 and a NATO member since 2009, but it is not a member of the Schengen area.

iii Between September 16th, 2015 and March 5th, 2016, a total of 658,068 migrants entered Croatia. On average, there were approximately 5,500 daily arrivals, with a peak of 11,000 on September 17th (Šelo Šabić and Borić 2016, 11). Between October 17th, 2015 and January 25th, 2016, 422,724 refugees crossed over into Slovenia. The peak period for migration was in October and November (Government of the Republic of Slovenia, 2015).

${ }^{\text {iv }}$ Data were collected in March and April 2016.

${ }^{\mathrm{v}}$ From September to the end of November, rtvslo.si had a coverage of approximately $33 \%$ of the population. About 500,000 different users from Slovenia visited rtvslo.si at least once in this period. This ranks rtvslo.si as the third most popular news website in Slovenia (data obtained from MOSS). Rtvslo.si is produced by the Multimedia Center, which is one of the program production units of the Slovenian public broadcaster RTV Slovenija. Rtvslo.si has several sections: Slovenija (Slovenia), Svet (World), Kultura (Culture), Šport (Sports), and Zabava/Razvedrilo (Entertainment; see Letno poročilo RTV [2015]), in which an average of approximately five articles per day covered migrants.

${ }^{v i} \mathrm{Hrt}$.hr is less widely read than rtvslo.si: it is the tenth most popular news website in Croatia. In September, October, and November 2015, it had approximately 9,150,000 page views per month. In the period examined, hrt.hr published approximately seven articles per day related to migrants. Hrt.hr consists of the following sections: Vijesti (News), Sport (Sports), Raspored (TV program), Magazin (Magazine), HRT prikazuje (HRT channels), Orkestri/Zbor (Orchestra/Choir), and Vrijeme i promet (Weather and Traffic).

${ }^{\text {vii }}$ In both languages, morphological variants of the stem and all cases were included in the search. viii Emphasis was defined according to size, foregrounding, clarity of focus, and centrality of the subject/object depicted.

ix "A metonym consists of a source concept/structure, which via a cue in a communicative mode (language, visuals, music, sound, gesture ...) allows the metonym's addressee to infer the target concept/structure" (Forceville 2009, 58).

${ }^{x}$ We follow Forceville's $(2016,58)$ understanding of multimodal metaphors and metonymies: their target and source are each represented predominantly or exclusively in different modes. 
Forceville considers, for instance, verbo-pictorial metaphors (in which the target is only given visually and the source is only given verbally, or vice versa) to be multimodal.

${ }^{x i}$ This framework has been expanded by Caple (2013), who introduces the Balance network, which particularly focuses on balance in visual composition, and Bednarek and Caple (2017).

${ }^{x i i}$ A thorough analysis of these multimodal texts in their entirety is a separate topic and beyond the scope of this study.

xiii Interestingly, some viewers with whom we discussed this image claim that the image also suggests the negatively evaluative metaphor MIGRANTS ARE WASTE.

${ }^{\text {xiv }}$ We consider the metaphorical construal in which the toy would be the source domain, and migrant children / migrants the target domain (MIGRANTS / MIGRANT CHILDREN ARE TOYS) less likely.

${ }^{x v}$ Although this image might have some critical potential in addressing the ongoing process of securitization (see Vezovnik [2018]; Buzan et al. [1998]), the majority of other images on rtvslo.si showing security objects are affirmative toward the security measures adopted by Schengen countries.

xvi Texts on the internet are almost always multimodal, and are a typical object of study of multimodal studies (see Jewitt, Bazemer, and O'Halloran 2016). Our texts consist of verbal elements, images, hyperlinks, and videos.

xvii The article headline below the image reads: "Opatovac: Building of Stable Objects Still Not Considered."

xviii These bodies, of course, do not necessarily have to be migrants' bodies. However, these images are parts of larger multimodal pieces predominantly or exclusively discussing migration, and these pieces contain additional images of migrants. This is why this interpretation automatically emerges.

${ }^{\text {xix }}$ Language expressions of such actions are immigrate, leave, arrive, etc.

${ }^{x x}$ The term "viewer(s)" in this study is used as in visual images studies: it refers to potential viewers and does not imply analyzing any concrete audiences. The "viewer" and his or her position is "imposed" by the sign-maker. This position is, for example, standing behind a person in the image if the person is not captured by the camera frontally.

${ }^{x x i}$ To us, this image is primarily metonymic; however, a few viewers with whom we discussed this image indicated that it also suggests a metaphorical link between people and mud. 
xxii Metaphors include mappings (regular correspondences) from the source (often concrete) into target domains (often abstract) that imply that we transfer our knowledge of the source to the target. Through the source domain of water, we transfer our knowledge about water to the target entity (e.g. migration, or any other entity for which we use water-related words and ideas in our conceptualization).

xxiii The headline reads: "Everyone cannot do whatever they want on the ground." The caption reads "One cannot expect small Slovenia to solve anything alone, this is a European problem, says Wolfgang, a volunteer from Austria."

xxiv Santa Ana's (1997) specification of the anti-immigrant metaphor (IMMIGRATION IS DANGEROUS WATER) is significant in this respect.

\section{Disclosure statement}

No potential conflict of interest was reported by the authors.

\section{Funding details}

University of Oslo, ILOS, Discourses of the Nation and the National.

\section{Notes on contributors}

Andreja Vezovnik is a sociologist and an Assistant professor in Media studies at the University of Ljubljana. Her main research areas include: migration discourses, semiotics of migration, food studies, studies of everyday life in socialist and post-socialist Yugoslavia.

Ljiljana Šarić is a professor of South Slavic linguistics at the University of Oslo. Her research areas are discourse analysis (specifically, discursive construction of cultural identity), cognitive linguistics, and South Slavic languages, literatures, and cultures. Her publications include Contesting Europe's Eastern Rim: Cultural Identities in Public Discourse (2010) and Transforming National Holidays: Identity Discourse in the West and South Slavic Countries, 1985-2010 (2012).

\section{ORCID}

Andreja Vezovnik http://orcid.org/0000-0001-5157-2365

Ljiljana Šarić http://orcid.org/0000-0003-4373-9182

\section{References}

"Hundreds of Refugees Stranded in Dire Conditions on Croatia/Slovenia." Amnesty International,
October
19
2015.
Accessed
August
17
2017. 
https://www.amnesty.org/en/latest/news/2015/10/hundreds-refugees-dire-conditions-croatiaslovenia-border/

Banks, James. 2012. "Unmasking Deviance: The Visual Construction of Asylum Seekers and Refugees in English National Newspapers." Critical Criminology 20 (3): 293-310.

Baek, Joonyeop. 2016. "Visual Metaphorical Conceptualization of the Syrian Refugees Crisis in Political Cartoons. MA thesis, Hankuk University of Foreign Studies.

Baker, Paul, Costas Gabrielatos, Majid Khosravinik Michael Krzyanowski, Tony Mcenery, Ruth Wodak. 2008. A Useful Methodological Synergy? Combining Critical Discourse Analysis and Corpus Linguistics to Examine Discourses of Refugees and Asylum Seekers in the UK Press.

Discourse \& Society 19 (3): 273-306.

Barthes, Roland. 1977. Image Music Text. London: Fontana Press.

Barthes, Roland. 1982. Camera Lucida: Reflections on Photography. New York: Hill and Wang. Batziou, Athanasia. 2011. 'Framing 'Otherness' in Press Photographs: The Case of Immigrants in Greece and Spain." Journal of Media Practice 12 (1): 41-60.

Bednarek, Monika and Helen Caple. 2017. The Discourse of News Values: How News

Organizations Create Newsworthiness Oxford: Oxford University Press.

Bleiker, Roland, David Campbell, Emma Hutchison, and Xzarina Nicholson. 2013. "The Visual Dehumanisaton of Refugees." Australian Journal of Political Science 48 (4): 398-416.

Buzan, Barry, Ole Wæver, and Jaap de Wilde. 1998. Security: A New Framework for Analysis.

Boulder, CO: Lynne Rienner Publishers.

Caple, Helen. 2013. Photojournalism: A Social Semiotic Approach. Besingstoke, UK: Palgrave Macmillan.

Carroll, Noël. 1996. “A Note on Film Metaphor.” Journal of Pragmatics 26 (6): 809-822.

Catalano, Theresa. 2016. Talking about Global Migration: Implications for Language Teaching. Bristol: Channel View Publications.

Catalano, Theresa, and Linda R. Waugh. 2013. "The Ideologies behind Newspaper Crime Reports of Latinos and Wall Street/CEOs: A Critical Analysis of Metonymy in Text and Image." Critical Discourse Studies 10 (4): 406-426.

Chouliaraki, Lillie. 2012. The Ironic Spectator: Solidarity in the Age of Post-Humanitarianism. Cambridge: Polity Press. 
Chouliaraki, Lillie, and Bolette B. Blaagaard. 2013. "Special Issue: The Ethics of Images." Visual Communication 12 (3): 253-259.

Dervinytè, Inga. 2009. "Conceptual Emigration and Immigration Metaphors in the Language of the Press: A Contrastive Analysis." Studies about Languages, no. 14: 49-55.

Domínguez, Martí, Felip Pineda, and Anna Mateu. 2014. "Life in a Nutshell: Evolution of a Migratory Metaphor in Spanish Cartoons." Media, Culture \& Society 36 (6): 810-825.

Douglas, Mary. 1984. Purity and Danger: An Analysis of the Concepts of Pollution and Taboo. London: Routledge.

El Refaie, Elisabeth. 2003. "Understanding Visual Metaphor: The Example of Newspaper Cartoons." Visual Communication 2 (1): 75-95.

Fahlenbrach, Kathrin. 2016. (ed.) Embodied Metaphors in Film, Television, and Video Games: Cognitive Approaches. New York: Routledge.

Feng, William Dezheng. 2017. Metonymy and Visual Representation: Towards a Social Semiotic Framework of Visual Metonymy. Visual Communication 6 (4): 441-466.

Fernández, Eliecer Crespo, and María Martínez Lirola. 2012. "Lexical and Visual Choices in the Representation of Immigration in the Spanish Press." Spanish in Context 9 (1): $27-57$.

Forceville, Charles. 1996. Pictorial Metaphor in Advertising. London: Routledge.

Forceville, Charles. 2009. "Metonymy in Visual and Audiovisual Discourse." In The World Told and the World Shown: Issues in Multisemiotics, edited by Eija Ventola, and Arsenio Jesús Moya Guijarro, 56-74. Basingstoke, UK: Palgrave MacMillan.

Forceville, Charles. 2016. "Visual and Multimodal Metaphor in Film: Charting the Field." In Embodied Metaphors in Film, Television, and Video Games: Cognitive Approaches, ed. by Kathrin Fahlenbrach, 145-161. New York: Routledge.

Forceville, Charles, and Eduardo Urios-Aparisi. 2009. "Introduction." In Multimodal Metaphor, edited by Charles Forceville, and Eduardo Urios-Aparisi, 3-18. Berlin: Mouton de Gruyter.

Giannakopoulos, Georgios. 2016. "Depicting the Pain of Others: Photographic Representations of Refugees in the Aegean Shores." Journal of Greek Media \& Culture 2 (1): 103-113.

Goatly, Andrew. 2007. Washing the Brain: Metaphor and Hidden Ideology. Amsterdam: John Benjamins.

Government RD. 2015. "Migration in Numbers." Accessed August 172017. http://www.vlada.si/fileadmin/dokumenti/si/projekti/2015/begunci/160202_migranti.pdf 
Hall, Stuart. 1981. "The Determination of News Photographs." In The Manufacture of News, edited by Stanley Cohen, and Jock Young, 226-243. London: Constable. Accessed August 18 2017.

https://qmro.qmul.ac.uk/xmlui/bitstream/handle/123456789/13709/Ibrahim\%20Imaging\%20the $\% 20 J u n g l e s \% 20$ of $\% 20$ Calais $\% 3 \mathrm{~A} \% 20 \mathrm{Media} \% 20 \mathrm{Visuality} \% 20$ and $\% 20$ the $\% 20$ Refugee $\% 20 \mathrm{Cam}$ p\%202016\%20Published.pdf?sequence $=1$

Huxford, John. 2001. "Beyond the Referential. Uses of Visual Symbolism in the Press." Journalism 2 (1): 45-71.

Ibrahim, Yasmin, and Anita Howarth. 2015. "Imaging the Jungles of Calais: Media Visuality and the Refugee Camp." Networking Knowledge: Journal of the MeCCSA Postgraduate Network 9 (4). Accessed August 18 2017. http://ojs.meccsa.org.uk/index.php/netknow/article/view/446 Jakešević, Ružica, and Siniša Tatalović. 2016. "Securitization (and De-Securitization) of the European Refugee Crisis: Croatia in the Regional Context." Teorija in praksa 53 (5): 1246-1264. Jonas, Hans. 1954. "The Nobility of Sight." Philosophy and Phenomenological Research 14 (4): 507-519.

Jewitt, Carey, Jeff Bazemer and Kay O'Halloran. 2016. Introducing Multimodality. New York:

Routledge.

Jordanova, Ludmilla. 1989. "Objects of Knowledge: A Historical Perspective on Museums." In The New Museology, edited by Peter Vergo, 22-40. London: Reaktion Books.

Kjeldsen, Jens E. 2017. "The Rhetorical and Argumentative Potentials of Press Photography.” In Multimodal Argumentation and Rhetoric in Media Genres, edited by Assimakis Tseronis, and Charles Forceville, 51-80. Amsterdam: John Benjamins.

Kress, Gunther, and Theo van Leeuwen. 1996. Reading Images: The Grammar of Visual Design. London: Routledge.

Kress, Gunther, and Theo van Leeuwen. 2001. Multimodal Discourse: The Modes and Media of Contemporary Communication. London: Arnold.

Ladić, Maja, and Katarina Vučko. 2016. "Slovenia's Response to Increased Arrivals of Refugees: We Don't Want Them, But We Also Don't Understand Why They Don't Want to Stay." In RazorWired: Reflections on Migration Movements through Slovenia in 2015, edited by Neža Kogovšek Šalamon i Veronika Bajt, 15-30. Ljubljana: Peace Institute. 
Lakoff, George, and Mark Johnson. 1980. Metaphors We Live By. Chicago: University of Chicago Press.

Lenette, Caroline, and Sienna Cleland. 2016. "Changing Faces: Visual Representations of Asylum Seekers in Times of Crisis." Creative Approaches to Research 9 (1): 68-83.

Lenette, Caroline, and Natasa Miskovic. 2016. “'Some Viewers May Find the Following Images Disturbing': Visual Representations of Refugee Deaths at Border Crossings." Crime, Media, Culture. doi: https://doi.org/10.1177/1741659016672716

Lidchi, Henrietta. 1997. "The Poetics and the Politics of Exhibiting Other Cultures." In Representation: Cultural Representation and Signifying Practices, edited by Stuart Hall, 151-222. London: Sage.

Littlemore, Jeannette. 2015. Metonymy. Hidden Shortcuts in Language, Thought and Communication. Cambridge: Cambridge University Press.

Machin, David, and Andrea Mayr. 2012. How to Do Critical Discourse Analysis. London: Sage.

Martínez Lirola, María. 2008. "A Critical Analysis of the Image of Immigrants in Multimodal Texts." Linguistics and the Human Sciences 2 (3): 377-397.

Martínez Lirola, María. 2014. "Exploring Visual Dysphemisms in Pieces of News Related to Immigrant Minors in a Spanish Newspaper." Visual Communication 13 (4): 405-427.

Martínez Lirola, María. 2017. "Linguistic and Visual Strategies for Portraying Immigrants as People Deprived of Human Rights.” Social Semiotics 27 (1): 21-38.

Martínez Lirola, María. 2016. "Multimodal Representation of Sub-Saharan Immigrants as Illegal:

Deconstructing Their Portrayal as Victims, Heroes and Threats in a Sample from the Spanish Press." Bulletin of Hispanic Studies 93 (4): 343-360.

Meadows, Bryan. 2006. "Distancing and Showing Solidarity via Metaphor and Metonymy in Political Discourse: A Critical Study of American Statements on Iraq during the Years 20042005." Critical Approaches to Discourse Analysis across Disciplines 1 (2): 1-17.

Mlekuž, Jernej. 2011. "Klepetalnica za predmete in ljudi.” In Klepetavi predmeti: ko predmeti spregovorijo o nas in drugih, edited by Jernej Mlekuž, 9-20. Ljubljana: Založba ZRC.

Özcan, Esra. 2013. "Lingerie, Bikinis and the Headscarf: Visual Depictions of Muslim Female Migrants in German News Media." Feminist Media Studies 13 (3): 427-442.

Özdemir, Özlem, and Emrah Özdemir. 2017. "Whose Problem Is It Anyway? The Depiction of Syrian Refugee Influx in Political Cartoons." Syria Studies 9 (1): 33-63. 
Permyakova, Tatiana M., and Olga L. Antineskul. 2016. “'Immigrant' in Russian and French Print Media (Linguistic and Visual Composition Analyses)." Journal of Intercultural Communication Research 45 (4): 319-337.

Radio televizija Slovenija. 2015. "Letno poročilo 2015." Accessed August 172017. http://www.rtvslo.si/files/letno_porocilo/letno_porocilo_2015_lektorirano.pdf

Santa Ana, Otto. 1997. "Empirical Analysis of Anti-Immigrant Metaphor in Political Discourse." University of Pennsylvania Working Papers in Linguistics 4 (1): 318-330.

Sindoni, Maria Grazia. 2016. “The Semantics of Migration'. Translation as Transduction: Remaking Meanings across Modes." Hermes - Journal of Language and Communication in Business, 55: 27-44.

Sperber, Dan, and Deirdre Wilson. 1995. Relevance Theory: Communication and Cognition. Oxford: Blackwell.

Šelo Šabić, Senada, and Sonja Borić. 2016. At the Gate of Europe. A Report on Refugees on the Western Balkan Route. Zagreb: Friedrich Ebert Stiftung.

Underhill, James W. 2011. Creating Worldviews: Metaphor, Ideology and Language. Edinburgh: Edinburgh University Press.

Vezovnik, Andreja. 2015. Balkan Immigrant Workers as Slovenian Victimized Heroes. Slavic Review (74) 2: 224-264.

Vezovnik, Andreja. 2017. Otherness and Victimhood in the Tabloid Press: The Case of the Refugee Crisis in Slovenske Novice. Dve domovini/Two homelands, 45: 121-135.

Vezovnik, Andreja. 2018. Securitizing Migration in Slovenia: A Discourse Analysis of the Slovenian Refugee Situation. Journal of Immigrant \& Refugee Studies 16 (1/2): 39-56.

Van Dijk, Teun A. 1998. Ideology: A Multidisciplinary Approach. London: Sage.

Van Leeuwen, Theo. 2008. Discourse and Practice: New Tools for Critical Discourse Analysis. Oxford: Oxford University Press.

Watson, D. Scott. 2009. The Securitization of Humanitarian Migrations: digging Moats and Sinking Boats. London: Routledge.

Womack, Mari. 2005. Symbols and Meaning: A Concise Introduction. Oxford: Alta Mira Press. Zelizer, Barbie. 2010. About to Die: How News Images Move the Public. Oxford: Oxford University Press. 
Table 1: Presentation of coded material for content-related categories

\begin{tabular}{|c|c|c|c|}
\hline Label & Category & Frequency & Percentages \\
\hline 1.1 & $\begin{array}{l}\text { Vehicles (planes, cars, boats, vans) belonging } \\
\text { to the police and military }\end{array}$ & 21 & $4 \%$ \\
\hline 1.2 & Infrastructure for detention (detention centers) & 63 & $13 \%$ \\
\hline 1.3 & $\begin{array}{l}\text { Border (border sign, checkpoint, border } \\
\text { control, fence, razor wire) }\end{array}$ & 123 & $25 \%$ \\
\hline 1.4 & Fingerprints, IDs, passports, paperwork & 6 & $1 \%$ \\
\hline 1.5 & $\begin{array}{l}\text { Objects belonging to migrants, things left } \\
\text { behind (life vest, shelters, tents, drawings, toys, } \\
\text { trash) }\end{array}$ & 32 & $7 \%$ \\
\hline 1.6 & $\begin{array}{l}\text { Transportation for migrants' travel (trains, } \\
\text { rails, buses, boats) }\end{array}$ & 32 & $7 \%$ \\
\hline 1.7 & $\begin{array}{l}\text { National and supranational symbols (flags, } \\
\text { political institutions) }\end{array}$ & 16 & $3 \%$ \\
\hline 1.8 & $\begin{array}{l}\text { Graphs, bar charts, pie charts, maps, tweets, } \\
\text { posters, campaigns, other non-photographic } \\
\text { images }\end{array}$ & 43 & $9 \%$ \\
\hline 1.9 & Humanitarian help & 16 & $3 \%$ \\
\hline 2.1 & $\begin{array}{l}\text { Active police agent, military (monitoring, } \\
\text { controlling, demonstrating power, fighting) }\end{array}$ & 7 & $1 \%$ \\
\hline 2.2 & $\begin{array}{l}\text { Active migrants (traveling, walking, riding } \\
\text { boats, trains, busses, protesting) }\end{array}$ & 51 & $11 \%$ \\
\hline 2.3 & $\begin{array}{l}\text { Passive police agent, military (standing, not } \\
\text { explicated) }\end{array}$ & 6 & $1 \%$ \\
\hline 2.4 & $\begin{array}{l}\text { Passive migrants (waiting, sitting around, } \\
\text { sleeping, standing) }\end{array}$ & 44 & $9 \%$ \\
\hline 2.5 & Civil society protesting & 4 & $1 \%$ \\
\hline
\end{tabular}




\begin{tabular}{|r|r|r|r|}
\hline 99 & OTHER & 19 & $4 \%$ \\
\hline $\begin{array}{r}\text { SUM: no. of } \\
\text { codes }\end{array}$ & & 483 & $100 \%$ \\
\hline
\end{tabular}

Table 2: Presentation of coded material: metonymy, metaphor, and symbol

\begin{tabular}{|r|l|r|r|}
\hline Label & Category & Frequency & Percentages \\
1 & Metonymy & 287 & $59 \%$ \\
\hline 2 & Metaphor & 30 & $6 \%$ \\
\hline 3 & Symbol & 166 & $34 \%$ \\
\hline 99 & OTHER & 0 & $0 \%$ \\
\hline SUM: no. of & & 483 & $100 \%$ \\
codes & & & \\
\hline
\end{tabular}

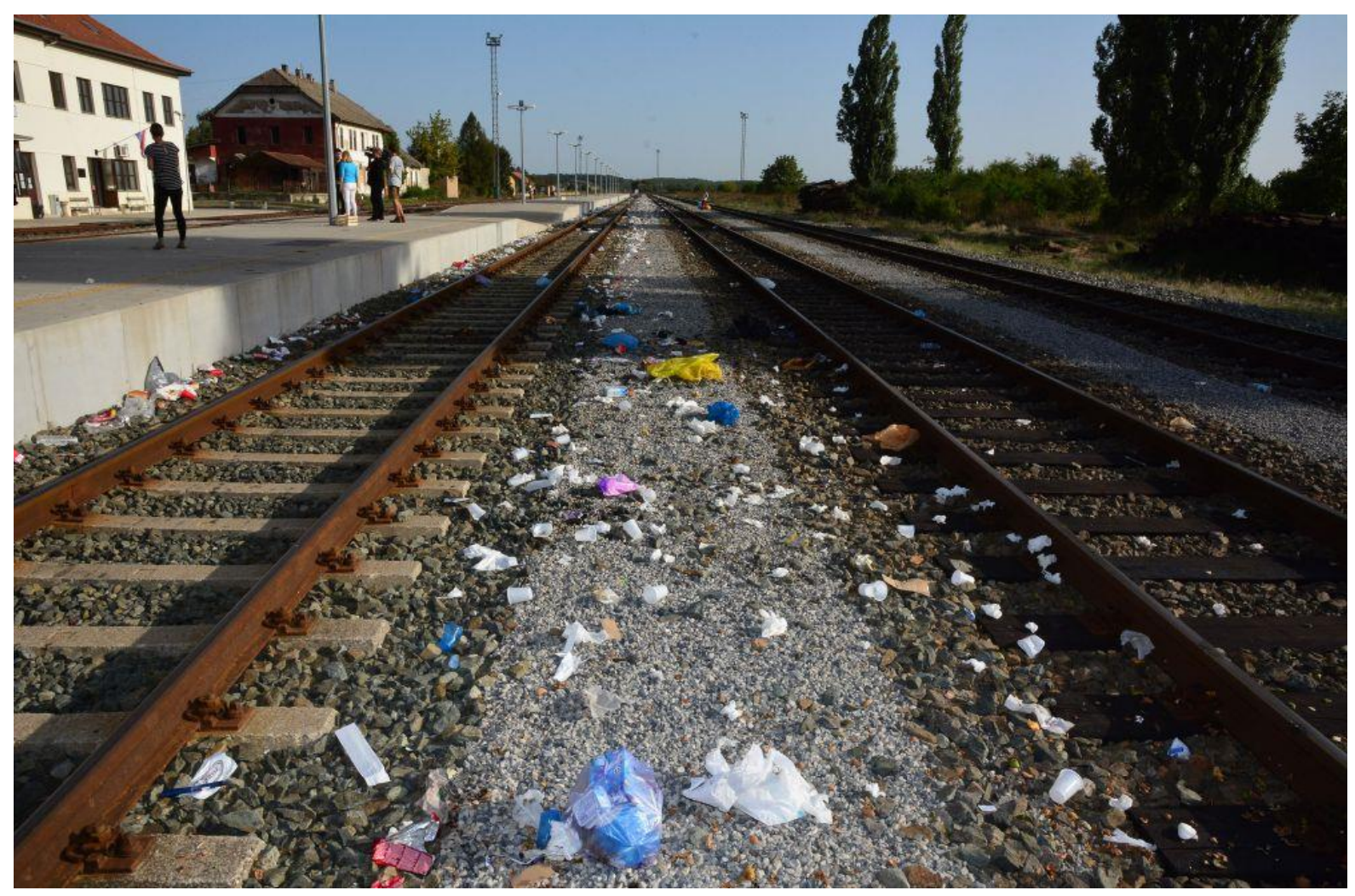

Figure 1: Source: http://vijesti.hrt.hr/299246/u-hrvatsku-uslo-vise-od-11-000-migranata-zatvoreno-7granicnih-prijelaza-prema-srbiji 


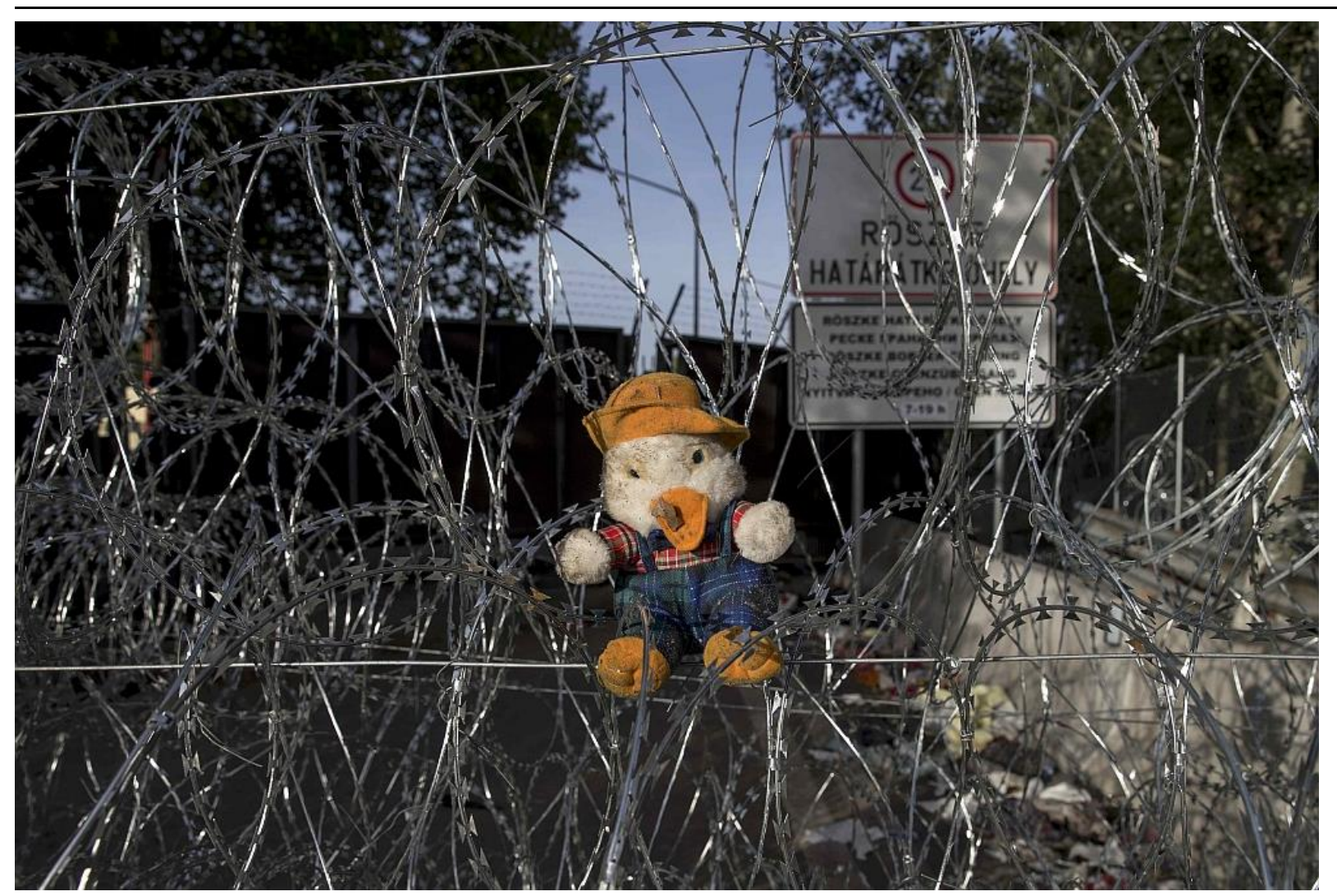

Figure 2: Source: http://www.rtvslo.si/svet/v-avstrijo-v-dnevu-in-pol-vstopilo-22-tisoc-

prebeznikov/374444



Figure 3: Source: http://www.hrt.hr/301079/vijesti/u-hrvatsku-uslo-vise-od-87-tisuca-izbjeglica 


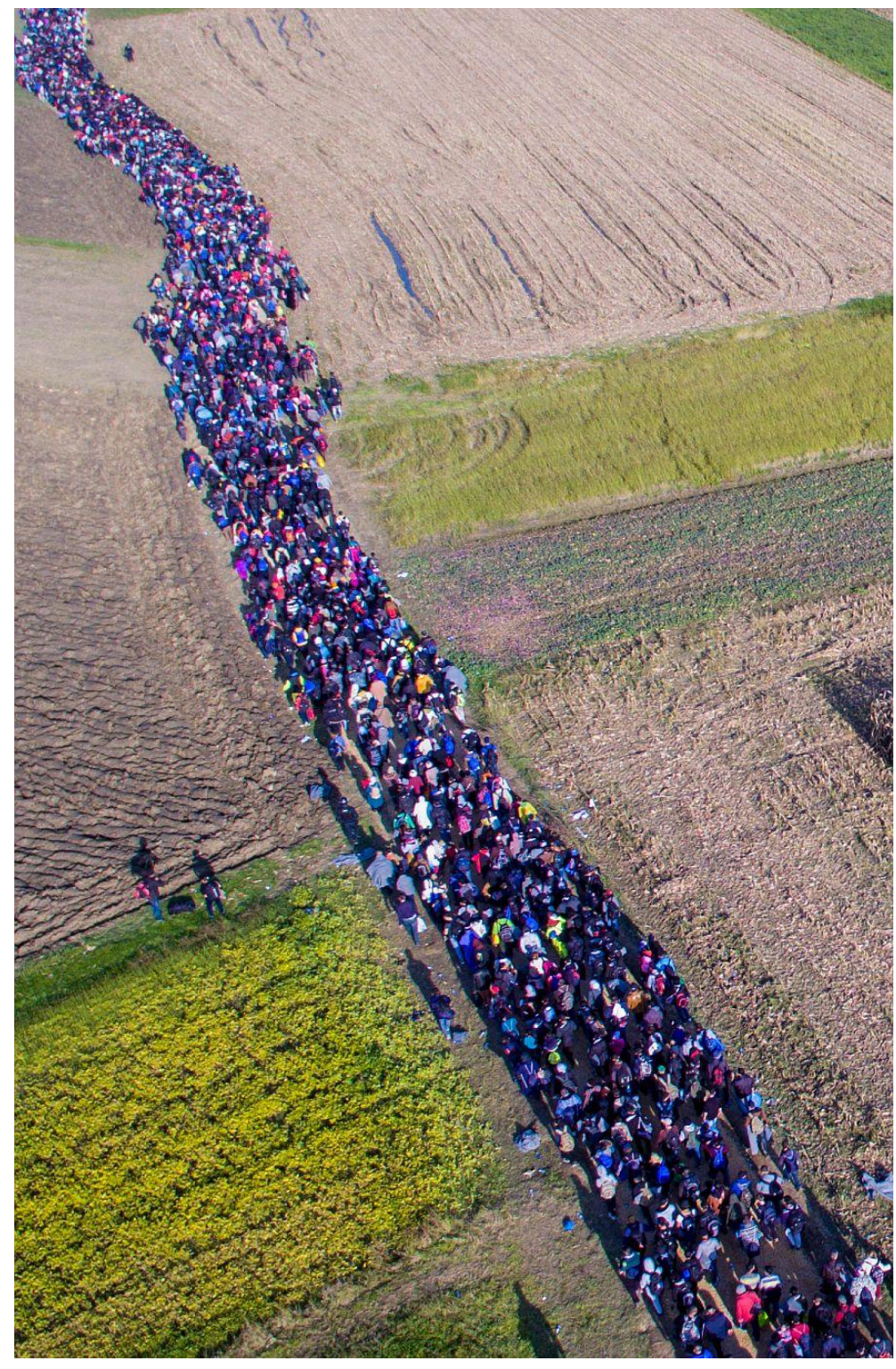

Figure 4: Source: http://www.rtvslo.si/slovenija/ne-more-vsak-na-terenu-poceti-kar-ga-je-volja/377195 